\title{
Leucorredução como prevenção de reações transfusionais: uma revisão da literatura
}

\author{
Leukorreduction with prevention of transfusion reaction: a review of the literature
}

\author{
Leucorreducción como prevención de reacciones transfusionales: uma revisión de la \\ literatura
}

Ana Caroline Cardoso da Silva1*, Ana Carolina Garcia Braz Trovão.

\begin{abstract}
RESUMO
Objetivo: Revisar a literatura sobre a leucorredução como prática de prevenção de reações transfusionais (RT). Métodos: Trata-se de uma revisão sistemática dos estudos publicados nos últimos 10 anos nas bases de dados, utilizando-se descritores adequados. Foram excluídos aqueles que não relacionaram o objetivo do estudo ou se publicados anterior a 2009. Resultados: Dos 76 artigos selecionados, cinco foram validados. Houve uma prevalência da produção científica pelos Estados Unidos. Todos os artigos concordaram com a eficácia da leucorredução sobre as RT, defendendo seu uso universal pré-armazenamento, porém, dois pontuaram dúvida sobre o uso da leucorredução em cirurgias cardíacas e sobre a efetiva redução da transmissão de citomegalovírus, necessitando de mais estudos. Uma limitação encontrada foi a falta de continuidade das pesquisas pelo alto custo da leucorredução universal. Considerações finais: A leucorredução é um método eficaz para prevenção de RT, além de diminuir a ocorrência de aloimunizações por antígeno de histocompatibilidade (HLA), exposição ao citomegalovírus e outras doenças transmissíveis via parenteral. Um fator limitante foi o alto custo do procedimento, resultando no uso desigual entre os países.
\end{abstract}

Palavras-chave: Transfusão de sangue, Reações transfusionais, Leucócitos, Leucaférese, Prevenção e controle.

\begin{abstract}
Objective: To review the literature on leukoreduction as a practice to prevent transfusion reactions (RT). Methods: This is a systematic review of studies published in the last 10 years in databases, using appropriate descriptors. Those who did not relate the study objective or if published before 2009 were excluded. Results: Of the 76 articles selected, five were validated. There was a prevalence of scientific production by the United States. All articles agreed with the efficacy of leukoreduction on RT, defending its universal pre-storage use, however, two reported doubt about the use of leukoreduction in cardiac surgeries and about the effective reduction of cytomegalovirus transmission, requiring further studies. One limitation found was the lack of continuity of research due to the high cost of universal leukoreduction. Final considerations: Leukoreduction is an effective method for the prevention of RT, besides reducing the occurrence of alloimmunizations by histocompatibility antigen (HLA), exposure to cytomegalovirus and other communicable diseases via parenteral. A limiting factor was the high cost of the procedure, resulting in unequal use among.
\end{abstract}

Key words: Blood transfusion, Transfusion reaction, Leukocytes, Leukapheresis, Prevention and control.

\section{RESUMEN}

Objetivo: Revisar la literatura sobre la leucorreducción como práctica para la prevención de reacciones transfusionales (RT). Métodos: Esta es una revisión sistemática de los estudios publicados en los últimos 10 años en las bases de datos, utilizando descriptores adecuados. Se excluyeron aquellos que no relacionaron el objetivo del estudio o si fueron publicados antes de 2009. Resultados: De los 76 artículos seleccionados, cinco fueron validados. Hubo el predomino de la producción científica de los Estados Unidos. Todos los artículos coincidieron con la eficacia de la leucorreducción en la RT, defendiendo su uso universal prealmacenamiento, sin embargo, dos señalaron dudas sobre el uso de la leucorreducción en cirugías cardíacas y sobre la reducción efectiva de la transmisión de citomegalovírus, requiriendo más estudios. Una limitación encontrada fue la falta de continuidad de la investigación debido al alto costo de la leucorreducción universal. Consideraciones finales: La leucorreducción es un método eficaz para prevencíon de la RT, además de reducir la aparición de aloinmunizaciones por antígeno de histocompatibilidad (HLA), exposición a citomegalovirus y otras enfermedades transmisibles por vía parenteral. Un factor limitante fue el alto costo del procedimiento, lo que resultó en un uso desigual entre países.

Palabras clave: Transfusión de sangre, Reacciones transfusionales, Leucocitos, Leucocitaféresis, Prevención y control.

${ }^{1}$ Centro Universitário Municipal de Franca (Uni-FACEF), Franca - SP. *E-mail: anacardoso1407@gmail.com

Financiamento: Bolsa de Iniciação Científica Uni-FACEF 2019/2020. 


\section{INTRODUÇÃO}

A terminologia "transfusão sanguínea" é difusamente conhecida, embora poucos saibam a real técnica do procedimento. Para que ela ocorra, é necessário o cumprimento de diversos protocolos pré e pós-doação, tanto aos doadores quanto aos receptores. O doador cadastrado no sistema de cada Hemocentro, de maneira voluntária, passará por etapas de pré-triagem e triagem clínica, a fim de verificar as condições de aprovação para a doação de sangue, para garantir tanto a segurança transfusional do doador quanto a do paciente receptor (BIAGINI S e ALBIERO A, 2018)

O objetivo da segurança transfusional é reforçar a importância do uso de testes sorológicos no doador e no receptor, de modo a garantir o reconhecimento de doenças pré ou pós-transfusionais, esclarecendo o momento de contaminação e quais pacientes devem ser avisados, pois o doador e o receptor podem estar contaminados e desconhecerem sua morbidade (BONEQUINI JUNIOR P e GARCIA PC, 2017).

Algumas estratégias de captação de doadores são desenvolvidas pelos bancos de sangue a fim de aumentar o número de doadores e estoque consequentemente. O objetivo é torná-lo doador de repetição, pois essa fidelidade torna seu perfil conhecido e mais confiável (LUZO ACM, 2010; RODRIGUES RSM e REIBNITZ KS, 2011; GIACOMINI L e FILHO WDL, 2010; MARTINEZ EZ, et al., 2020).

Luzo ACM (2010) traz o exemplo de campanhas de conscientização em Pernambuco, com entrega de panfletos explicativos sobre o tema, evidenciando o perfil dos doadores de repetição, no qual $77,1 \%$ eram homens entre 18-24 anos, com doação espontânea, com fator influenciador de histórico de doadores na família.

O sangue doado pode ser dividido em hemocomponentes e hemoderivados. Os hemocomponentes são obtidos pela coleta de sangue total (ST) e separados por centrifugação em concentrado de hemácias $(\mathrm{CH})$, concentrado de plaquetas (CP), plasma fresco de 24 horas (P24) ou congelado (PFC) e crioprecipitado (CRIO). O PFC sofre procedimento químico e formam os hemoderivados que são: albumina, globulinas e concentrado de fatores de coagulação, através de procedimentos químicos realizados por empresas especializadas (BIAGINI S e ALBIERO A, 2018).

Para a doação, coleta-se cerca de 450 mililitros $(\mathrm{mL})$ de sangue, na qual serão pesquisadas: tipagem sanguínea $\mathrm{ABO} / \mathrm{RH}$, Pesquisa de Anticorpos Irregulares (PAl) por Coombs Indireto, prova de compatibilidade e testes sorológicos como: Hepatite B e C, sífilis, doença de Chagas, AIDS e vírus HTLV pré-armazenamento. Em caso de positividade, a Vigilância Epidemiológica e o doador serão notificados, com convocação de retorno dos envolvidos ao hemocentro para esclarecimentos (BIAGINI S e ALBIERO A, 2018).

Além disso, orienta-se que o paciente evite atividade física extenuante, faça pequenos lanches e aumente a ingesta hídrica nas próximas $24 \mathrm{~h}$. Aconselha-se o retorno ao hemocentro se o local de coleta permanecer em sangramento mesmo após $4 \mathrm{~h}$ com oclusão local ou presença de qualquer alteração cutânea (BRAZ AC, et al., 2014).

O uso terapêutico da transfusão deve ser orientado e prescrito por um médico, seguindo critérios bem definidos, haja vista que todo processo possui um risco ao receptor (BIAGINI S e ALBIERO A, 2018). A indicação transfusional é realizada por um médico e cumpre critérios clínicos e laboratoriais (Tabela 1), sendo contraindicado com objetivo profilático, expansão volêmica ou cicatrização. Estes podem diferir entre o Protocolo de cada serviço de saúde (BONEQUINI JUNIOR P e GARCIA PC, 2017).

Os critérios clínicos e laboratoriais estão correlacionados e sua indicação pode ser assim relacionada: 1) Hemoglobina $(\mathrm{Hb})$ menor ou igual a cinco, independente de sinais clínicos; 2) $\mathrm{Hb}$ entre seis e oito: transfundir se presença de fatores de risco cardiovascular e/ou presença de sinais de hipóxia; 3) Hb entre oito e 10: transfundir apenas se presença de sinais de hipóxia, se menores que 65 anos e quadro hemorrágico agudo com instabilidade hemodinâmica (baixo débito cardíaco, frequência cardíaca entre 100 e 120 batimentos por minuto, hipotensão arterial, queda do débito urinário, frequência respiratória maior que 20 incursões respiratórias por minuto, enchimento capilar maior que dois segundos e alteração no nível de consciência); 4) Se Hb maior que 10, não se realiza transfusão (BONEQUINI JUNIOR P e GARCIA PC, 2017). 
A transfusão sanguínea pode culminar em uma complicação chamada Reação Transfusional (RT), definida como qualquer evento de caráter prejudicial consequente à administração de sangue ou de hemocomponentes em um indivíduo, podendo ser classificada em imediata ou tardia, a depender do momento do seu aparecimento, sendo ele antes ou após 24 horas, respectivamente (BIAGINI S e ALBIERO A, 2018).

A RT mais comum é a Reação Febril Não Hemolítica (RFNH), imediata e imunomediada por anticorpos antiplaquetários do receptor ou citocinas de leucócitos do doador, caracterizada por aumento de temperatura em pelo menos um grau comparado ao momento pré-transfusional. Geralmente ocorre ao final do processo ou poucas horas após. Em toda RT deve-se interromper imediatamente a transfusão, manter o acesso venoso e administrar antitérmico para controlar o sintoma (BELLINTANI LM, 2019; BONEQUINI JUNIOR P e GARCIA PC, 2017).

O grupo das reações transfusionais trazem alguns sinais e sintomas, dentre eles os mais frequentes são: febre alta ou aumento de pelo menos $1^{\circ} \mathrm{C}$ em relação ao valor pré-transfusional; tremores e calafrios, alterações de pele, hiper ou hipotensão, náuseas, dispneia, sibilos, dor torácica, abdominal ou lombalgia e até hemorragias (BIAGINI S e ALBIERO A, 2018).

Uma forma de prevenção de RT é utilizar um hemocomponente especial, podendo ser por lavagem, irradiação ou leucorredução. Na lavagem o $\mathrm{CH}$ e CP recebem solução isotônica de cloreto de sódio estéril para eliminar a maior quantidade possível de plasma. Na irradiação usa-se raios gama para impedir a multiplicação de linfócitos. A leucorredução remove os leucócitos por um filtro específico, resultando em uma quantidade menor que $5 \times 10^{6}$ de leucócitos por unidade, feita pré-estocagem (também chamada de bancada) ou pós estocagem (a beira leito momento da transfusão). Os CP podem ser leucorreduzidas por plasmaférese (BONEQUINI JUNIOR P e GARCIA PC, 2017; BIAGINI S e ALBIERO A, 2018; LIMA DPDS e IMAMURA KB, 2017).

O Ministério da Saúde indica o procedimento por transfusão de bancada para eliminar a maior quantidade possível dos leucócitos antes que estes se degradem, pois isso liberaria citocinas inflamatórias como a interleucina 1, interleucina 6 e fator de necrose tumoral, facilitando assim a ocorrência de uma reação transfusional (BIAGINI S e ALBIERO A, 2018; LIMA DPDS e IMAMURA KB, 2017).

Há algumas indicações para uso hemocomponente leucorreduzido: prevenção da aloimunização em pacientes politransfundidos, casos de distúrbio hematológico, prevenção de transmissão de citomegalovírus (CMV), transplantados CMV negativos, pacientes em quimioterapia, recém-nascido com peso inferior a 1200 gramas, transfusão intrauterina, prevenção de recorrência de RFNH, a partir da $3^{a}$ transfusão de hemácias ou plaquetas, síndromes de imunodeficiências congênitas, doenças onco-hematológicas graves até esclarecimento diagnóstico, ou gestantes com sorologia não-reativa ou desconhecida para CMV (BIAGINI S e ALBIERO A, 2018).

Embora seja um procedimento útil em diversas comorbidades, há pessoas com RT que necessitam ser politransfundidos. Diversos estudos têm discutido métodos de obtenção de hemocomponentes com a menor quantidade possível de leucócitos a fim de minimizar as Reações Transfusionais. Há consenso na comunidade científica sobre a significativa importância clínica da leucorredução, dessa forma, os estudos têm buscado realizar métodos eficazes e também de baixo custo para realizá-la, a fim de tornar um procedimento útil e de fácil acesso (DZIK S, et al., 2000).

A partir dessa problemática, foi realizada uma revisão sistemática da literatura sobre a prática da leucorredução de hemocomponentes como prevenção de reações transfusionais. Tal problemática remete à importância de identificar as produções científicas acerca da leucorredução na prática clínica como prevenção de reações transfusionais, os métodos utilizados e sua eficácia, além de reconhecer os benefícios secundários da leucorredução para o paciente ou para tratamento e/ou prognóstico de patologias preexistentes, a fim de contribuir para a possibilidade de universalizar a prática de redução de leucócitos dos hemocomponentes. 


\section{MÉTODOS}

Foi realizada uma revisão sistemática da literatura sobre a prática da leucorredução de hemocomponentes como prevenção de reações transfusionais nos últimos 10 anos, nas bases de dados LILACS, Pubmed, Cochrane, Scielo e Biblioteca Virtual em Saúde, com os descritores "Transfusão", "Reações Transfusionais", "Leucaférese", "Prevenção \& Controle", "Leucorredução". Foram selecionados artigos com idiomas em português, inglês e espanhol, sem restrição de conteúdo integral e que abordassem o tema central de pesquisa, dentre os anos de 2009 a 2021. Artigos que não respeitaram os critérios de inclusão, com publicações repetidas em diferentes bases de dados, que restringiam o acesso ao conteúdo completo do estudo ou que utilizaram a revisão de literatura como metodologia de estudo foram excluídos da amostra. Assim, após a aplicação dos critérios de inclusão e exclusão previamente estabelecidos, foram validados cinco artigos validados, dentre as 76 literaturas inicialmente selecionadas (Figura 1), a partir da identificação e triagem dos artigos.

Do total de 76 obras, 45 foram excluídas na primeira análise por estarem fora do período delimitado ou não abordarem o tema central. Seguida de uma segunda análise refinada e integral dos artigos, no qual 31 deles foram excluídos por estarem repetidos, com acesso restrito ao conteúdo ou por possuírem metodologia de revisão de literatura. A seguir serão descritas as cinco produções científicas validadas nesta pesquisa, segundo os critérios de exclusão e inclusão

Figura 1 - Análise dos artigos para estudo.

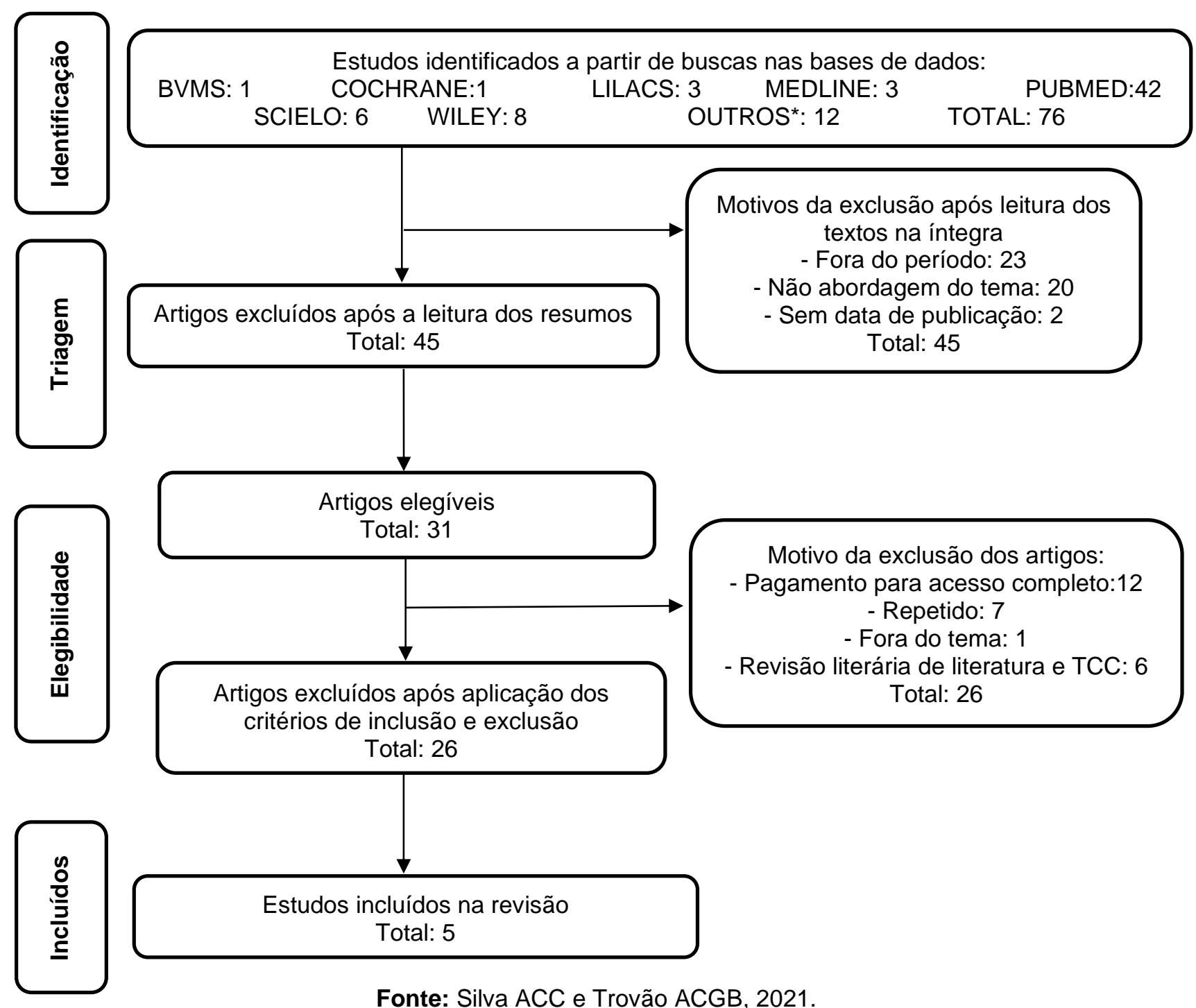


Para melhor organização dos estudos selecionados, foi formulado um quadro com alguns dados de cada artigo contendo: o nome completo do artigo, periódico publicado e ano de publicação, país de origem, faixa etária dos participantes, a amostragem $(\mathrm{N})$, o delineamento metodológico, aspectos éticos, por fim, as principais conclusões de cada artigo.

De acordo com o caráter metodológico deste estudo, houve dispensa de submissão ao Comitê de Ética em Pesquisa (CEP) da instituição.

\section{RESULTADOS}

Após a triagem inicial e seleção dos cinco artigos para a elaboração desse estudo, é possível notar uma alternância entre os períodos de maior publicação nesta vertente, foram encontrados três trabalhos em 2010, um em 2016 e um em 2017, demonstrando um declínio sobre a produção científica na área nos últimos anos em diversos países, e referente a isso, destaca-se em produção os Estados Unidos em primeiro lugar, seguido do Brasil e Itália, com produção de quatro e um artigos para cada país, respectivamente. Sobre as bases de dados, notou-se a prevalência da Pubmed com quatro artigos (Quadro 1).

Quadro 1 - Classificação de artigos selecionados de acordo com o título, autores, fonte e país de publicação literária.

\begin{tabular}{|c|c|c|c|c|c|}
\hline & $\begin{array}{l}\text { BASE } \\
\text { DE } \\
\text { DADOS }\end{array}$ & TÍTULO & $\begin{array}{l}\text { PRIMEIRO } \\
\text { AUTOR e } \\
\text { ANO }\end{array}$ & PERIÓDICO & PAÍS \\
\hline 1 & LILACS & $\begin{array}{l}\text { Soroprevalência de infecção por } \\
\text { citomegalovírus em doadores de } \\
\text { sangue saudáveis no Estado da } \\
\text { Bahia, Brasil. }\end{array}$ & $\begin{array}{l}\text { MATOS SB, et } \\
\text { al., } 2010\end{array}$ & $\begin{array}{c}\text { Revista Brasileira } \\
\text { de Hematolgia e } \\
\text { Hemoterapia. }\end{array}$ & Brasil - SP \\
\hline 2 & Pubmed & $\begin{array}{l}\text { A leucorredução pré- } \\
\text { armazenamento melhora os efeitos } \\
\text { do envelhecimento no sangue } \\
\text { armazenado. }\end{array}$ & $\begin{array}{l}\text { PHELAN HA, } \\
\text { et al., } 2010\end{array}$ & $\begin{array}{c}\text { The Journal of } \\
\text { Trauma. }\end{array}$ & EUA \\
\hline 3 & Pubmed & $\begin{array}{l}\text { Programa de leucorredução para } \\
\text { transfusões de hemácias em cirurgia } \\
\text { coronária: associação com redução } \\
\text { da lesão renal aguda e mortalidade } \\
\text { hospitalar }\end{array}$ & $\begin{array}{l}\text { ROMANO G, } \\
\text { et al., } 2010\end{array}$ & $\begin{array}{l}\text { The Journal of } \\
\text { Thoracic and } \\
\text { Cardiovascular } \\
\text { Surgery. }\end{array}$ & Itália \\
\hline 4 & Pubmed & $\begin{array}{l}\text { Infecção pós-natal por } \\
\text { citomegalovírus: um estudo piloto de } \\
\text { eficácia comparativa da segurança } \\
\text { da transfusão usando estratégia de } \\
\text { transfusão somente leucorreduzida. }\end{array}$ & $\begin{array}{l}\text { DELANEY M, } \\
\text { et al., } 2016\end{array}$ & Transfusion & EUA \\
\hline 5 & Pubmed & $\begin{array}{l}\text { A leucorredução de concentrados de } \\
\text { hemácias atenua as propriedades } \\
\text { pró-inflamatórias } \\
\text { microvesículas derivadas das } \\
\text { armazenamento. }\end{array}$ & $\begin{array}{l}\text { RICHTER JR, } \\
\text { et al., } 2017\end{array}$ & $\begin{array}{l}\text { The Journal of } \\
\text { Surgical } \\
\text { Research }\end{array}$ & EUA \\
\hline
\end{tabular}

Fonte: Silva ACC e Trovão ACGB, 2021.

No âmbito da faixa etária dos artigos, esta variou substancialmente, no qual três estudos abordaram apenas adultos, variando de 18 a 72 anos e um abordou bebês com até 40 dias de vida. Sobre o delineamento metodológico, dois trabalhos realizaram coorte, um prospectivo e um retrospectivo, e dois realizaram estudos experimentais. Com relação à amostragem, as duas maiores foram de um estudo de coorte retrospectivo e de um experimental ( $\mathrm{N}=1034$ e $\mathrm{N}=636$ ). Em relação aos dois estudos experimentais, apenas um constou a aprovação pelo Comitê de Ética. 
Dos artigos incluídos, todos foram favoráveis ao uso de leucorredução como ferramenta para diminuir a prevalência das $\mathrm{RT}$, no qual $60 \%(\mathrm{n}=3)$ deles mencionaram utilizar leucorredução pré-armazenamento e apoiaram seu uso de forma universal (Quadro 2). Ainda, dois estudos de revisão de literatura não especificaram a forma de leucorredução estudada, mas concordam que é uma manobra eficaz tanto para redução de RT quanto para a disseminação de doenças, levantando resultados incertos sobre a leucorredução de forma benéfica em cenário de cirurgias cardíacas e no qual sua amostra de estudo foi pequena, concluindo que, mesmo apoiando a eficácia do uso da leucorredução pré-transfusão, há a necessidade de maiores estudos na área para um posicionamento claro e concreto (MATOS SB, et al., 2010; PHELAN HA, et al., 2010; ROMANO G, et al., 2010; DELANEY M, et al., 2016; RICHTER JR, et al., 2017; MACHADO MB e PASSOS SD, 2019).

Quadro 2 - Análise dos artigos segundo faixa etária, amostragem, delineamento metodológico, aspectos éticos e principais conclusões.

\begin{tabular}{|c|c|c|c|c|c|}
\hline & $\begin{array}{l}\text { Faixa } \\
\text { etária } \\
\text { (anos) }\end{array}$ & Amostra & $\begin{array}{l}\text { Delineamento } \\
\text { metodológico }\end{array}$ & $\begin{array}{l}\text { Aspectos } \\
\text { éticos }\end{array}$ & Conclusão \\
\hline 1 & $18-66$ & 636 & Experimental & $\begin{array}{l}\text { Aprovado } \\
\text { pelo Comitê } \\
\text { de Ética }\end{array}$ & $\begin{array}{l}\text { Pela alta soroprevalência de CMV, a } \\
\text { leucorredução mostra-se importante para } \\
\text { pacientes com alto risco de desenvolver } \\
\text { infecção grave. Não menciona a forma da } \\
\text { leucorredução estudada. }\end{array}$ \\
\hline 2 & $23-60$ & 399 & $\begin{array}{c}\text { Coorte } \\
\text { retrospectiva }\end{array}$ & $\begin{array}{l}\text { Aprovado } \\
\text { pelo Comitê } \\
\text { de Ética }\end{array}$ & $\begin{array}{l}\text { Nossos dados sugerem que os efeitos } \\
\text { deletérios do envelhecimento no sangue } \\
\text { depositado são melhorados pelo PS-LR } \\
\text { Utilizou leucorredução pré-armazenamento }\end{array}$ \\
\hline 3 & $53-72$ & 1034 & Coorte & $\begin{array}{l}\text { Aprovado } \\
\text { pelo Comitê } \\
\text { de Ética }\end{array}$ & $\begin{array}{l}\text { Este é o primeiro estudo que demonstra que } \\
\text { a leucorredução está associada a menor } \\
\text { taxa de Injúria Renal Aguda. Este estudo } \\
\text { sugere a necessidade de mais ensaios } \\
\text { clínicos prospectivos para demonstrar a } \\
\text { eficácia da leucorredução no cenário } \\
\text { cirúrgico cardíaco, assim como demonstrar } \\
\text { a relação entre mortalidade reduzida e } \\
\text { incidência reduzida da insuficiência renal. } \\
\text { Utilizou leucorredução pré-armazenamento }\end{array}$ \\
\hline 4 & $\begin{array}{l}\text { Até } 40 \\
\text { dias de } \\
\text { vida }\end{array}$ & 20 & $\begin{array}{c}\text { Estudo } \\
\text { prospectivo }\end{array}$ & $\begin{array}{l}\text { Aprovado } \\
\text { pelo Comitê } \\
\text { de Ética }\end{array}$ & $\begin{array}{l}\text { Com base neste estudo piloto, conclui-se } \\
\text { que usando a leucorredução, não houve } \\
\text { caso de transmissão transfusional de CMV. } \\
\text { É necessário um estudo maior para } \\
\text { determinar com segurança a estratégia mais } \\
\text { eficaz para a prevenção da transmissão } \\
\text { transfusional de CMV na população de } \\
\text { bebês de até } 40 \text { dias. Não menciona a forma } \\
\text { da leucorredução utilizada }\end{array}$ \\
\hline 5 & $\begin{array}{l}\text { Não } \\
\text { consta }\end{array}$ & $\begin{array}{l}\text { Não } \\
\text { consta }\end{array}$ & $\begin{array}{l}\text { Experimental } \\
\text { (camundongo) }\end{array}$ & Não consta & $\begin{array}{l}\text { A leucorredução pré-armazenamento das } \\
\text { unidades de glóbulos vermelhos } \\
\text { empacotados (pRBC) reduz a formação as } \\
\text { propriedades pró-inflamatórias das } \\
\text { microvesículas, que por sua vez diminui a } \\
\text { lesão pulmonar após hemorragia e } \\
\text { ressuscitação. Utilizou leucorredução pré- } \\
\text { armazenamento }\end{array}$ \\
\hline
\end{tabular}

Fonte: Silva ACC e Trovão ACGB, 2021. 


\section{DISCUSSÃO}

Para garantir a segurança transfusional e evitar complicações como a RT, faz-se uso de hemocomponentes especiais como a leucorredução, na qual retira os leucócitos do material doado a fim de minimizar citocinas inflamatórias e facilitar a RT (BIAGINI S e ALBIERO A, 2018).

De forma geral, o objetivo central dos artigos inicialmente selecionados foi analisar a eficácia do uso da leucorredução como fator minimizador de RT, concordando com a proposta desta revisão sistemática (PHELAN HA, et al., 2012; HEWITT PE, et al., 2013; DOLLARD SC, et al., 2013; DOUET JY, et al., 2015; RICHTER JR, et al., 2017; SILLIMAN CC, et al., 2017; DELIZARI DS, 2015; PROCTOR MC e LEIBY DA, 2015).

Foi possível notar a prevalência de publicações nas Américas ( $n=4,80 \%)$, sendo os Estados Unidos da América (EUA) o protagonista, com três publicações, seguido de Brasil e Itália com apenas uma publicação para cada país. Contudo, é notável que estas produções devem ser estimuladas de maneira geral, incluindo outros países, uma vez que a transfusão é um procedimento comum na prática clínica e pode ser aprimorada e utilizada de forma universal (FAUSTINO GF, et al., 2015).

Referente aos cinco artigos selecionados, Matos SB, et al. (2010) concordam com o uso benéfico da leucorredução para redução de citomegalovírus (CMV) em pacientes com alto risco para desenvolver infecção grave, mas sem mencionar o tipo de leucorredução. Destaca ser preciso ter cautela em pacientes com alto índices de anticorpos contra o citomegalovírus (anti-CMV) de imunoglobulina G (IgG) e necessidade de maiores estudos nesse grupo para compreender o processo de reativação ou reinfecção por este vírus.

Alguns estudos fomentam que o armazenamento por si só causa acúmulo de substâncias inflamatórias advindas da degradação de leucócitos, de forma fisiológica, como leucotrienos, proteínas de leucócitos, células chamadas CD40 ligante (CD40L), plaquetas contaminantes e ocorrência de aloimunizações por HLA. O papel da leucorredução se enquadra na redução da concentração de leucócitos e consequentemente menor taxa de substâncias inflamatórias, reduzindo a chance de ocorrer RT (SILLIMAN CC, et al., 2017). Assim, após fazerem estudos com materiais leucorreduzidos pré-armazenamento, duas publicações selecionadas sugerem que a desleucocitação auxilia em menores efeitos deletérios sobre o uso dos hemocomponentes armazenados por longos períodos (PHELAN HA, et al., 2010; RICHTER JR, et al., 2017).

No estudo de coorte de Romano G, et al. (2010), a leucorredução foi usada em cirurgias coronarianas e foi estudado a relação com lesão renal aguda. Este foi o primeiro trabalho confirmatório levantando a eficácia da desleucocitação sobre a menor taxa de Injúria Renal Aguda, com reflexo na redução da morbimortalidade. Entretanto, sobre a cirurgia coronariana, os autores são inconclusivos e sugerem a necessidade de maiores pesquisas para a confirmação do benefício. Neste, foi utilizado material leucorreduzido pré-armazenamento.

Para a prevenção dessa transmissão, a Emory University realizou um estudo utilizando amostras soronegativa para CMV associadas a leucorredução e concluíram que usando apenas a transfusão leucorreduzida, nenhum caso de transmissão foi detectado, porém, um fator limitante foi o número de sua amostra, pontuando que um estudo maior se faz necessário para garantir segurança às informações (DELANEY M, et al., 2016). Dessa forma, Delaney M, et al. (2016) mesmo concordando com o benefício do procedimento, também se posicionaram cautelosos sobre o uso da leucorredução universal, devido a sua amostragem reduzida $(n=20)$, sem mencionar o uso de hemocomponente leucorreduzido pré ou pósarmazenamento.

O estudo de Richter JR, et al. (2017) vem para complementar dúvidas levantadas por estudos prévios sobre o uso da leucorredução universal como forma de prevenção de lesão pulmonar aguda (TRALI), concluindo que a redução de substâncias pró-inflamatórias na microvasculatura pela desleucocitação estaria relacionada a diminuição de lesão pulmonar.

Embora não inclusos aos estudos selecionados, outros trabalhos trouxeram reflexões importantes como Ziemann M e Henning H (2010) concordam com o estudo de Matos SB, et al. (2010) e acrescentam sobre maiores cuidados aos produtos doados por pacientes recém-soropositivos para CMV, sendo a leucorredução 
uma medida para evitar disseminação da doença. Trazem que o tempo de armazenamento das bolsas de hemocomponente pode alterar a estabilidade do CMV e esse aspecto deve ser investigado. Não mencionam sobre qual a forma da leucorredução estudada.

Mesmo com autores descrevendo o benefício da leucorredução na transmissão de CMV, há estudos que contestam quais pacientes devem recebê-lo, como por exemplo na prevenção da transmissão do CMV em pacientes imunossuprimidos como neonatos e receptores de transplantes (WEISBERG SP, et al., 2017). Por fim, neste estudo, não foi possível distinguir a relação de melhora ou piora na qualidade de vida após o uso da leucorredução em produtos para tratamento em momento pós-operatório, em situações de trauma e na vigência de infecções, pois os estudos com os devidos temas estavam anteriores ao ano de 2009 delimitado nesta pesquisa.

Em meio ao novo cenário de pandemia vivido desde 2020, autoridades afirmam o risco teórico da transmissão de SARS-CoV-2, conhecido como COVID-19 devido a possibilidade de encontrá-lo no plasma sanguíneo. Foi encontrado apenas um estudo com a temática em hemoterapia, abordando inclusive novas formas de tentativa de proteção à transmissão do vírus via bancos de sangue no Japão, por meio da realização de pesquisa de RNA viral e rastreio de anticorpos com RT-PCR aos materiais advindos de Wuhan desde fevereiro de 2020, porém sem abranger o tema de reações transfusionais relacionadas ao COVID-19. Foram realizadas novas pesquisas literárias até abril de 2021, entretanto, não houve estudo disponível atual abrangendo a área de leucorredução associada a reações transfusionais (CHANG L, et al., 2020).

Nota-se que um fator limitante ao uso da leucorredução está associado ao alto custo do procedimento, culminando na diferença entre os países sobre adotar ou não a leucorredução universal. Desta forma, é notável que o incentivo financeiro estimularia a maior produção científica de leucorredução entre as diversas áreas da medicina, abrangendo inclusive aquelas com limitada produção científica atual, como por exemplo em cenário de traumas, em SARS-CoV2 e no pós-operatório, uma vez que a escassez de estudos foi um fator limitante nessa pesquisa (BORDIN JO e FABRON JR, 1997).

\section{CONSIDERAÇÕES FINAIS}

A leucorredução mostra-se como ferramenta eficaz para prevenção de reações transfusionais, além de diminuir a ocorrência de aloimunizações por HLA, exposição ao CMV e outras doenças transmissíveis via parenteral, e a redução da taxa de injúria renal aguda. Até o momento não se encontraram evidências para usá-la como prevenção de lesão pulmonar aguda relacionada à transfusão e em cirurgias cardíacas. Até o momento não há publicação científica sobre a associação entre SARS-CoV-2 e o uso da leucorredução. Um fator limitante ressaltado pelos estudos foi o alto custo do procedimento e consequente uso desigual entre os países. Portanto, faz-se necessário maiores investimentos por parte dos serviços, bem como maior produção científica na área.

\section{AGRADECIMENTOS E FINANCIAMENTO}

Agradeço ao Centro Universitário Municipal de Franca por possibilitar o fornecimento de bolsa de estudo através da Iniciação Científica Uni-FACEF e também a minha orientadora por todo o ensinamento, tempo dedicado e empenho para o desenvolvimento deste trabalho.

\section{REFERÊNCIAS}

1. BELLINTANI LM. Hemocentro RP. Cremesp, 2019.

2. BIAGINI S, ALBIERO A. Manual de Transfusão. Fundação Pró-Sangue Hemocentro de São Paulo, São Paulo, 2018; $1-39$.

3. BONEQUINI JÚNIOR P, GARCIA PC. Manual de Transfusão Sanguínea para Médicos. Universidade Estadual Paulista "Júlio de Mesquita Filho", HC/FMB, 2017.

4. BORDIN JO, FABRON AJR. Aplicação clínica de filtros leucocitários. Revista da Associação Médica Brasileira, 1997; 43(3): 205-208.

5. BRAZ ACG, et al. Translation into Portuguese and validation of the Blood Donation Reactions Inventory. Revista Brasileira de Hematologia e Hemoterapia [online], 2014; 36: 139, 2014. 
6. CHANG L, et al. Coronavirus Disease 2019: Coronaviruses and Blood Safety. Transfusion Medicine Reviews, 2020; 34 (2): 75-80.

7. DELANEY M, et al. Postnatal cytomegalovirus infection: a pilot comparative effectiveness study of transfusion safety using leukoreduced-only transfusion strategy. Transfusion, 2016; 56 (8): 1945-1950.

8. DELAZARI DS. CD40 e transfusão de sangue: uma revisão integrativa. Trabalho de Conclusão de Curso (TCC em Medicina) - Faculdade de Medicina de Marília, 2015; 22p

9. DOLLARD SC, et al. Measurements of human herpesvirus 8 viral load in blood before and after leukoreduction filtration. Transfusion, 2013; 53 (2): 2164-2167.

10. DOUET JY, et al. Leukoreduction and blood-borne vCJD transmission risk. Current Opinion in Hematology, 2015; 22(1): 36-40.

11. DZIK S, et al. Leukocyte reduction of blood components.Transfusion Medicine Reviews, 2000; 14(1): 34-52.

12. FAUSTINO GF, et al. O ciclo de produção do sangue e a transfusão: o que o médico deve saber. Revista Médica de Minas Gerais, 2015; 25(2): 269-279.

13. GIACOMINI L, FILHO WDL. Estratégias para fidelização de doadores de sangue voluntários e habituais. Acta Paulista de Enfermagem, 2010; 23(1): 65-72.

14. HEWITT PE, et al. Human T-lymphotropic virus lookback in NHS Blood and Transplant (England) reveals the efficacy of leukoreduction. Transfusion, 2013; 53(10): 2168-2175.

15. LIMA DPDS, IMAMURA KB. A desleucocitação de hemocomponentes sanguíneos e sua utilização na transfusão de sangue no Brasil. NewsLab, São Paulo, 2017.

16. LUZO ACM. Características que determinam um doador de repetição, quais seriam? Revista Brasileira de Hematologia e Hemoterapia, São Paulo, 2010; 32(5): 348.

17. MACHADO MB, PASSOS SD. Severe pertussis in childhood: update and controversy - systematic review / Coqueluche grave na infância: atualização e controvérsias - revisão sistemática. Revista Paulista de Pediatria, Jundiai, 2019; 37(3): 351-362.

18. MARTINEZ, E. Z. et al. Recommendations for application and interpretation of the Blood Donor Satisfaction Questionnaire (BDSQ). Hematology, Transfusion and Cell Therapy, 2020; 1-7.

19. MATOS SB, et al. Seroprevalence of cytomegalovirus infection among healthy blood donors in Bahia State, Brazil. Revista Brasileira de Hematologia e Hemoterapia, São Paulo, 2010; 32(1).

20. PHELAN HA. Prestorage leukoreduction ameliorates the effects of aging on banked blood. The Journal of Trauma, 2010; 69(2): 330-337.

21. PHELAN HA, et al. Prestorage leukoreduction abrogates the detrimental effect of aging on packed red cells transfused after trauma: a prospective cohort study. American Journal of Surgery, 2012; 203(2): 198-204.

22. PROCTOR MC, LEIBY DA. Do leukoreduction filters passively reduce the transmission risk of human granulocytic anaplasmosis? Transfusão, 2015; 55(6): 1242-1248.

23. RICHTER JR, et al. Leukoreduction of packed red blood cells attenuates proinflammatory properties of storage-derived microvesicles. Journal of Surgical Research, 2017; 223: 128-135.

24. RODRIGUES RSM, REIBNITZ KS. Estratégias de captação de doadores de sangue: uma revisão integrativa da literatura. Texto \& Contexto - enfermagem, 2011; 20(2): 384-391.

25. ROMANO G, et al. Leukoreduction program for red blood cell transfusions in coronary surgery: association with reduced acute kidney injury and in-hospital mortality. The Journal of Thoracic and Cardiovascular Surgery, 2010, 140(1): 188195.

26. SILLIMAN CC, et al. The accumulation of lipids and proteins during red blood cell storage: the roles of leucoreduction and experimental filtration. Blood Transfusion, 2017; 15: 131-136

27. WEISBERG SP, et al. Survey on Transfusion-Transmitted Cytomegalovirus and Cytomegalovirus Disease Mitigation. Archives of Pathology \& Laboratory Medicine, 2017; 141(12): 1705- 1711.

28. ZIEMANN M, HENNIG H. Effet de la déleucocytation des concentrés érythrocytaires sur les réactions transfusionnelles. Transfusion Clinique et Biologique, 2010; 17: 14-19. 